\section{PNEUMATIC CLOCKS}

To distribute the time with accuracy and uniformity in importance. This problem has been all but completely solved by the pneumatic clocks erected since March last in the principal streets of Paris and among a considerable number of subscribers, who, for a halfpenny a day, receive the time from the observatory every minute without winding up or any care on their part. The details of the system established in Paris we take from an article by M. E. Hospitalier in a recent number of La Nature. The system consists of (I) a central station where the compressed air is produced and sent every minute through the system of tubes; (2) a distributing system of tubes with ramifications to streets and houses; (3) a series of

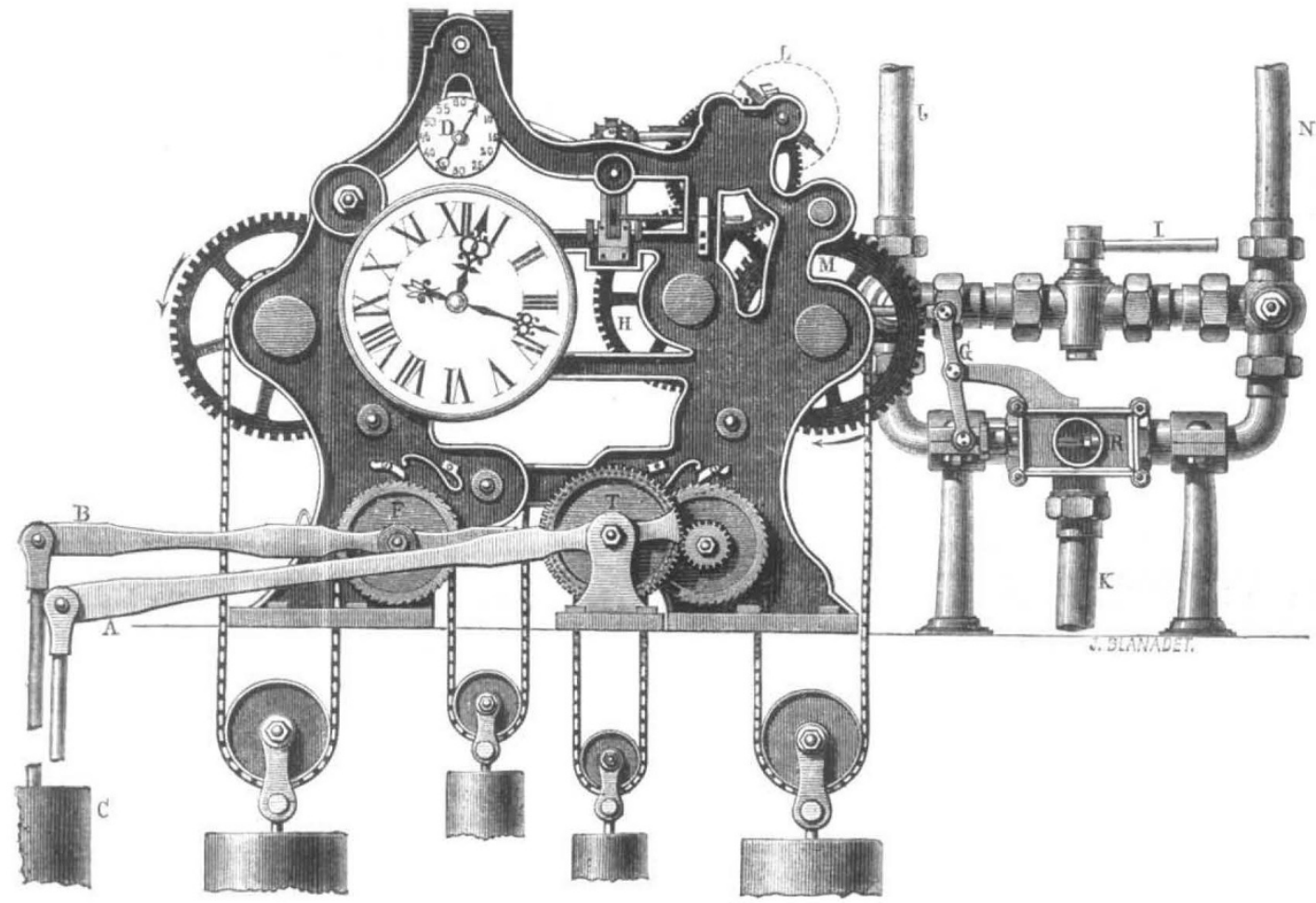

FIG. r.-Distributing Clock of Compressed Air.

dials with pneumatic receivers established in the public streets and in private buildings.

At the central works a steam-engine sets in motion two pumps, which compress air into a large reservoir of about eight cubic metres, at a pressure of five atmospheres. This compressed air, by means of a special regulator, is transmitted to a second chamber called the distributing reservoir, where the pressure is kept at seventenths of an atmosphere by means of a simple automatic apparatus. This reservoir is put into communication every minute with the main distributing pipes for twenty seconds by means of a distributing clock shown in Fig. $\mathrm{I}$. The distributing clock comprises two quite distinct movements : the left movement is intended to set the clock going in the ordinary manner; the right movement is specially intended to work the distributing valve $R$. The seconds-hand is at $\mathrm{D}$. At the beginning of each minute the air of the distributing reservoir arriving by the tube $J$ in the distributing box is sent into the main distributing pipes by the tube M. At the end of twenty seconds a displacement of the lever G places the valve $R$ in its second position. The tube N then communicates with the tube $\mathrm{K}$, open to the atmosphere, while the tube $J$ no longer communicates either with $\mathrm{K}$ or with $\mathrm{N}$. The valve $\mathrm{R}$ remains 40 seconds in this position, to complete the minute, when a new displacement of the valve again places $\mathrm{J}$ in connection with $\mathrm{N}$, and so on. All these displacements of the valve are effected by means of gearings arranged in the works of the distributing clock. The compressed air of the main pipes is utilised to wind up automatically the two movements by means of the levers $A$ and $B$, which are connected with pistons placed in the cylinders $\mathrm{C}$, and

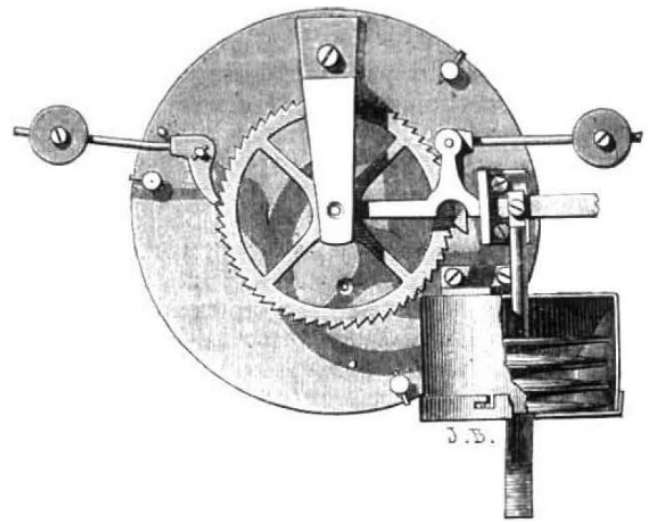

FIG, 2.-Dial Mechanism of Street and Private Clocks.

raised every minute by the compressed air to a distance exactly equal to that through which the motor weight has descended during the preceding minute. There is no need, therefore, to trouble about the winding up of the 
distributing clock. This clock is regulated by the Observatory, by hand; but soon a special system will be established, by which the exact time will be distributed from the Observatory by electricity. As the system is established in duplicate at the central works, should anything go wrong with one clock the other is put in working order in a few seconds. The function of the distributing clock may be performed by the hand by working properly, every minute, the three-way tap, I, which plays exactly the part of the valve $R$.

For the system of distribution the air is sent every minute into the tube $\mathrm{N}$, which bifurcates into a certain number of smaller branches, forming so many networks completely separate and independent, so that a derangement of one of the systems does not affect the others. The principal tubes, carric d underground, are of wrought iron, and have

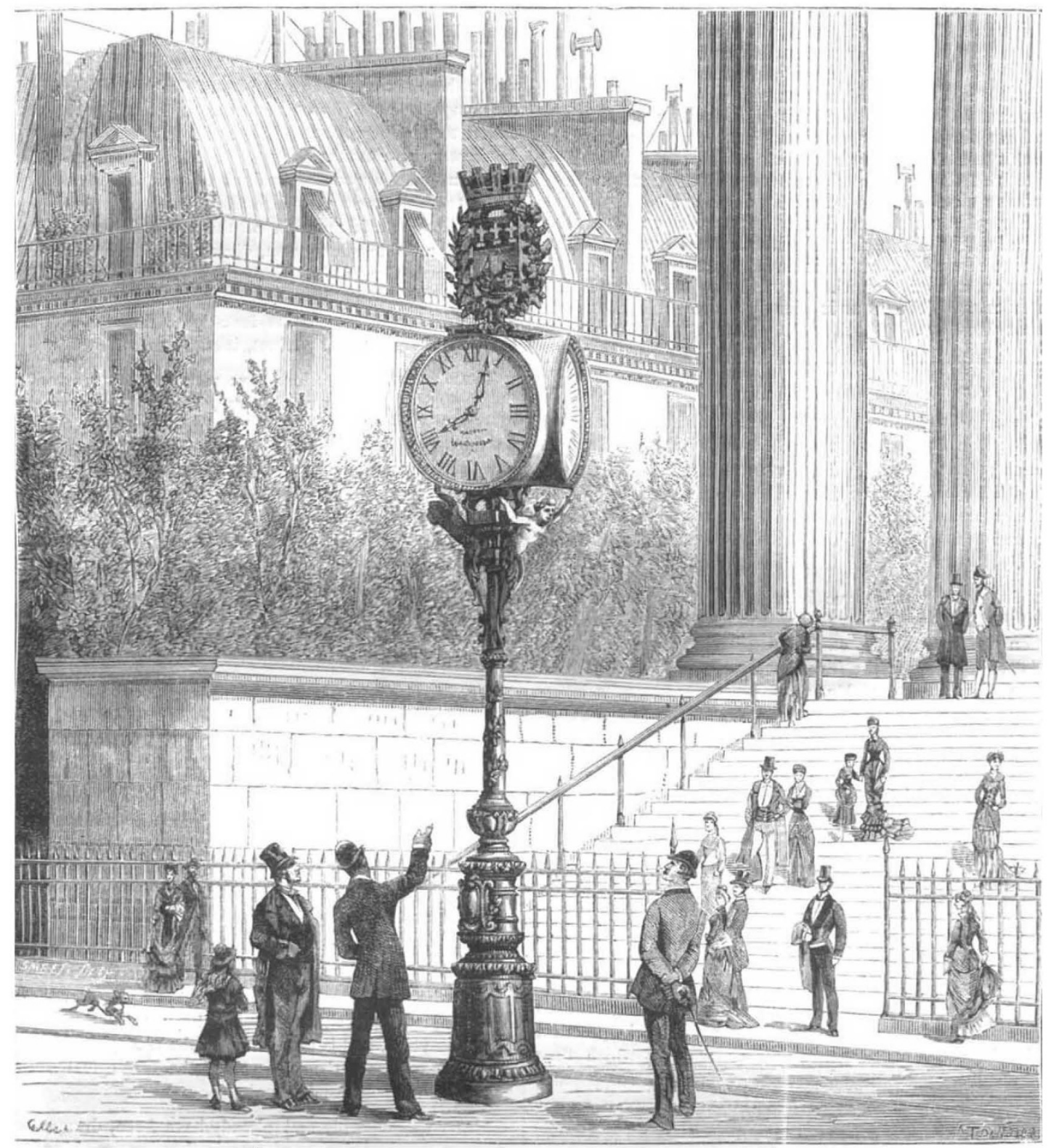

FIG. 3.-The Pneumatic Clock on the Place de la Madeleine.

an internal diameter of 27 millimetres. The tubes placed in private houses are of lead, $15 \mathrm{~mm}$. in diameter ; in apartments and passages this diameter is reduced to $6 \mathrm{~mm}$., and the tube attached to the clock, in lead or india-rubber covered with silk, is only $3 \mathrm{~mm}$. in diameter. With a pressure of seven-tenths of an atmosphere, by leaving the distributing system for 20 seconds in communication with the distributing reservoir, as we have said, it is easy to set the clocks going several miles from the central works, notwithstanding the inevitable escape from the pipes Differences have occasionally been observed between some of the clocks, probably in most cases the results of mischievous meddling; these, and other accidents, however, become fewer and fewer, and will no doubt gradually. disappear. Owing to the division of the service into various distinct networks, any flaw is soon detected and easily repaired.

Whatever be the form or size of the dial, public or 
private, the mechanism is always the same. A caoutchouc bellows, like that used in Walker's pneumatic air-bells, is in communication with the main pipes. Every minute the pressure of the air raises it (Fig. 2); this bellows acts on a lever which draws a wheel of sixty teeth, in the axis of which is fixed the minute-hand. The wheel makes one-sixtieth of a revolution; a ratchet-click, shown on the left of the toothed wheel, prevents any return of the wheel. The movement of the hour-hand is effected by means of a small train of wheels, which is not represented in the figures. This small and very simple mechanism may be placed with the greatest facility in the interior of existing clocks, without changing the external form, substituting it for the old movement.

By means of a second bellows, the function of which is to wind up the bell of a pneumatic clock on a slightly different system, we may establish striking clocks. The price of the former to subscribers is 5 centimes a day, the striking clocks costing 6 centimes.

In Fig. 3 is represented the pneumatic clock of the Place de la Madeleine, furnished with its three dials, the movement of each of which is independent. The letters are clear on a blue ground. At night a jet of gas lights the interior, and the hour is clearly discernible at a considerable distance.

\section{NOTES}

WE have much pleasure in stating that Her Majesty has been graciously pleased to grant to the widow of John Allan Broun a pension of $75 l$. per annum. In NATURE, vol, xxi. p. II2, will be seen a full account of the life and works of that distinguished magnetician and meteorologist, whose life may truly be said to have been sacrificed through his devotion to the cause of scientific research.

THE following grants have been made from the Research Fund of the Chemical Society :- - rol. to Mr. Kingzett for experiments on the atmospheric oxidation of phosphorus; $25^{\prime}$. to Mr. Watson Smith for the investigation of the di-napthyls and phenyl napthalene ; $25 l$. to Messrs. Bailey and Munro for investigations of the colour reactions of certain metals and metallic solutions.

Mr. Auberon Herbert is anxious to preserve our ancient monuments, but thinks the method proposed in Sir John Lubbock's Bill all wrong and unnecessarily harassing ; indeed in his letter in Tuesday's Daily News he scents communism in Sir John's enterprise. He deprecates Government interference at all, and thinks the only effectual and enlightened method to be the education of the people into an intelligent respect for all our ancient monuments, a respect which would be a sufficient guarantee for their protection. Might not Mr. Herbert get Lord Norton to compile a series of reading-lessons on archocology after his lordship has completed the botanical reading-book to which we referred last week? These lessons might take practical effect in the course of a generation or two, by which time probably there would be no ancient monuments for popular protection. The obtuseness of Mr. Herbert's letter is almost phenomenal.

University COllege, London, is anxious to complete its buildings, and in conncction with this purpose a meeting was held at the Mansion IIouse last Friday. We have frequently had occasion to speak of the great services rendered by the institution to the raising and broadening of education in this country. It has not only itself aimed to carry out a high standard of education, but has given a strong and healthy impulse to older institutions, and led, directly or indirectly, to the establishment of other institutions in which science has its fair pluce. Of the desirability of completing the buildings of Uni- versity College there can be little doubt. The sum required is large-105,000l.; but if Edinburgh could raise 90,000l. for a similar purpose surely the wealthiest city of the wealthiest country in the world need have little difficulty in raising the sum required. Of this sum $20,000 \%$. has already been subscribed; about the balance we trust there will be no difficulty.

In connection with the recent meeting to raise funds for the completion of University College buildings, Prof. Ray Lankester writes to yesterday's Times, animadverting in strong terms on the scandalous misappropriation of the funds left by Sir Thomas Gresham "for the purpose of providing a college which should rival the Universities of Oxford and Cambridge in the completeness of its appointments and bring the highest education to the very doors of the citizens of London." Prof. Lankester suggests that the present representatives of the Corporation, who appear so anxious to promote the educational

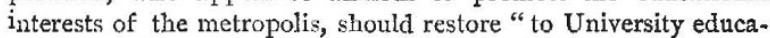
tion in London a fair portion of the sum which the Corporation of London, in days long past, diverted to its own benefit from Sir Thomas Gresham's trust." But could not the Gresham funds be included in the inquiry of the Commission now being appointed by Government to investigate the whole question of the City Corporations? If not, it ought to be.

Two important accessions have recently been received by the Herbarium of the Royal Gardens, Kew. The corporation of Carlisle has transferred to it the herbarium of Dr. Goodenough, who was formerly Bishop of the Diocese, and who died in 1827. This is rich in specimens of plants cultivated at Kew and Chelsea in the end of the last century, but which have hitherto been very imperfectly represented in the Kew Herbarium. The very extensive collections of mosses accumulated by the late Prof. Schimper of Strassburg, and upon which his well-known works upon this group of plants were based, has been purchased (together with the accompanying drawings and notes) from Prof. Schimper's family by the Baroness Burdett-Coutts, and also presented to Kew.

DR. M. C. Cooke having been placed by the India Office at the disposal of the authorities of the Royal Gardens, Kew, has now entered upon his duties as cryptogamist attached to the Herbarium, and will for the present take charge of the collections of non-vascular cryptogams.

Mr. H. A. Rolfe, lately a gardener in the employ of the Royal Gardens, Kew, has been appointed by the Civil Service Commissioners, after a competitive examination, to the vacant post of second assistant in the Herbarium of the same cstablishment.

DR. WOODWARD has been appointed keeper of the geological department of the British Museum in succession to Mr. Waterhouse, who resigned about three months ago. Dr. Woodward has occupied the position of assistant-keeper in the department for many years, and is the editor of the Geological Magazine, in which, as well as in the Fournal of the Geological Society, he has published numerous memoirs.

MANy lessons will, and already have been, drawn from the unprecedented explosion of gas in London on Monday; the results were disastrous enough, but we may congratulate ourselves that they were no worse. The science of the explosion is simple enough, as the daily papers have been telling the fublic; and when science is properly taught in our elementary schools such accidents can only be due to perversity, not lack of knowledge. We recommend this explosion and its immediate cause, to the consideration of Lord Norton.

OUR readers may remember that some months ago Sir William Thomson made several valuable suggestions as to the readjust- 